International Journal of Performance Arts and Digital Media, Volume 5 Number 1. (C) Intellect Ltd 2009. Article. English language. doi: 10.1386/padm.5.1.3/1

\title{
Lost in location - on how (not) to situate aliens
}

\section{Lone Koefoed Hansen Aarhus University, Denmark}

\begin{abstract}
The article investigates how users of personal satellite navigation devices (often referred to as sat-nav) are sometimes lost and led astray and argues that the satnav's aim to remove every insecurity about the correct route seems to remove the individual's conscious perception of the space traversed. While becoming destination aware, the individual loses her location awareness. The article proposes that the reason people get lost when using sat-nav is due to a wrong location-performative paradigm. As an alternative, the article introduces and analyzes two performance-related examples that illustrate an alternative locationperformative paradigm: Meredith Warner's Lost/Found knitting series and Etter and Schecht's Melodious Walkabout. In both examples, the artist's hand becomes the intermediary between alien and location. Thus, by exploring how wayfinding can be a poetically situated performance, the article examines how the growing locative media industry can learn from the location-aware performative strategies employed by artists who create situated and urban performances for the curious participant. The academic frames employed in the analysis draw on psychogeography, site-specific performance, social and cultural geography, and aspects of phenomenology.
\end{abstract}

\section{Introduction}

Since a road closure, dozens of drivers were blithely following directions from their satellite navigation systems, not realising that the recommended route goes through the ford. Every day since the main B4040 was closed after a wall collapsed on April 8 one or two motorists have been towed out, having either failed to notice or ignored warning signs. Some farmers have been charging $£ 25$ to give a tow with tractors. Lesley Bennett, a Luckington parish councillor, said: "When the car conks out the driver looks stunned. When you ask what happened, they say, "My sat-nav told me it was this way"'.

(Bruxelles 2006)

Even though this anecdote is at the spectacular end of the spectrum, there are many other stories of how drivers alien to the landscape in which they are driving are lost and led astray whilst believing they were on the right track. This is supported by survey findings: 'A Which? [a UK Consumers' Association] survey at the weekend found that 26 per cent of drivers who used sat nav had got lost doing so' (MetroUK 2007).

\section{Keywords}

satellite navigation locative media psychogeography site-specific performativity cultural geography mapping 


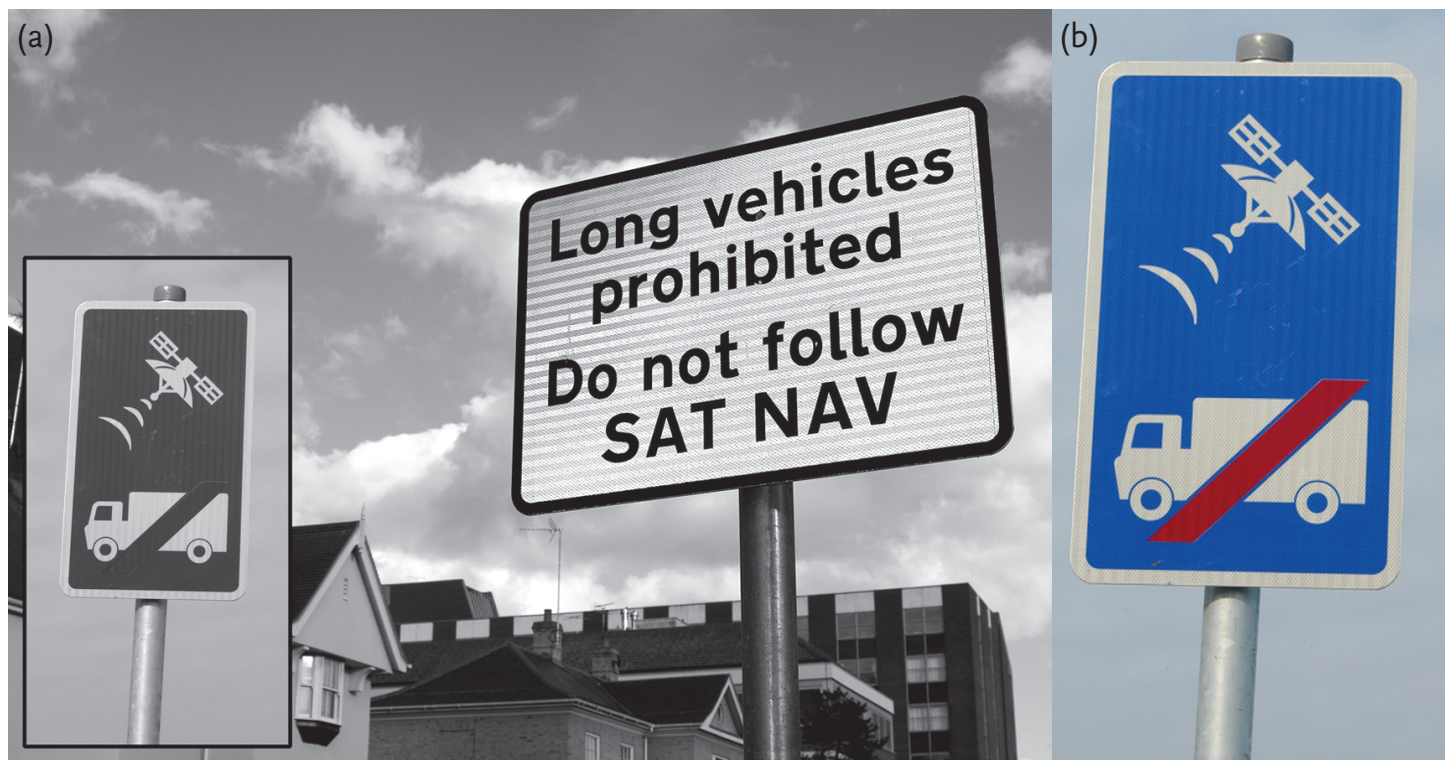

Figure 1: $(a, b)$ : Street signs warning drivers of driving the route suggested by the sat-nav. CC license from 'Unhindered by Talent'@Flickr.com

Apparently, the supposedly transparent and unobtrusive interface of the satellite navigation device (hereafter called sat-nav) found in many cars is in many cases a driver's worst nightmare. Many websites run by automotive associations are recognizing this and trying to educate drivers (Institute of Advanced Motorists 2007; The Automobile Association 2008). The frequency of sat-nav sidetrackings and experiences where people get stuck in streets that are too narrow for the car they are driving, or other similar incidents, has even created a new market for alert signs. New pictographs are needed when city councils have to alert drivers that they are trusting their sat-navs too much (see Figure 1).

However easily these stories can be dismissed as only happening to absent-minded people driving with their eyes closed, it does seem unlikely that this is the only reason. There are simply too many stories - some with more serious consequences than others. A technically oriented solution to the problem would be to demand more reliable and constantly updated maps so that the sat-nav's map contains no errors, which by inference would enable the driver to never be led into wrong places. Another possibility would be to blame technology: it is making robots out of people so that they do not even realize that they are about to drive into a lake or onto a closed road before they are actually stuck. There is, however, also a chance that the concept itself is flawed. You cannot neglect the existence of the odd absent-minded daydreamer, but I will argue in this article that these incidents do not happen because people are dumb, because they trust technology too much, or because the maps are not constantly updated.

Instead, this article will investigate how those sidetrackings can be understood and possibly even explained if one understands the satellite 
navigation device as a technology that performs a location. In this light, one might understand the repeated strayings as incidents that highlight how the device fails to situate the alien user because it is based on the wrong location-performative paradigm.

\section{Situating aliens}

With the purpose of establishing an image of what it means to be an alien, what it means to be situated and which role location specificity plays in all this, I will begin by introducing an art project where the artist's hand becomes the intermediary between the alien and the location, thus effectively de-alienizing the alien. Artist Meredith Warner has devised a project that concretely as well as metaphorically is concerned with the feeling of being lost and with the notions of location and situatedness. In her project 'Lost/Found knitting series' (Warner 2003) Warner re-knits lost and found woolen objects to the place where they were found (see Figure 2).

She carefully situates the lost objects in their new 'home' by meticulously integrating them into their new environment. With knitting needles as a tool her accomplishment is two-fold: while situating and de-alienizing the alien, she also amplifies specific aspects of her current surroundings, thus situating herself in the often otherwise characterless location. Consequently, the location-dependent knitting also quite literally forces her to acknowledge the specificity of the place herself with the result that she becomes a less-alien alien and the location becomes a more specific location.

Even though there are very few similarities between a human being and a woollen mitten, Warner's art project can serve as a metaphor for an alternative sat-nav paradigm. Both Warner (the sat-nav) and the mitten (the driver)

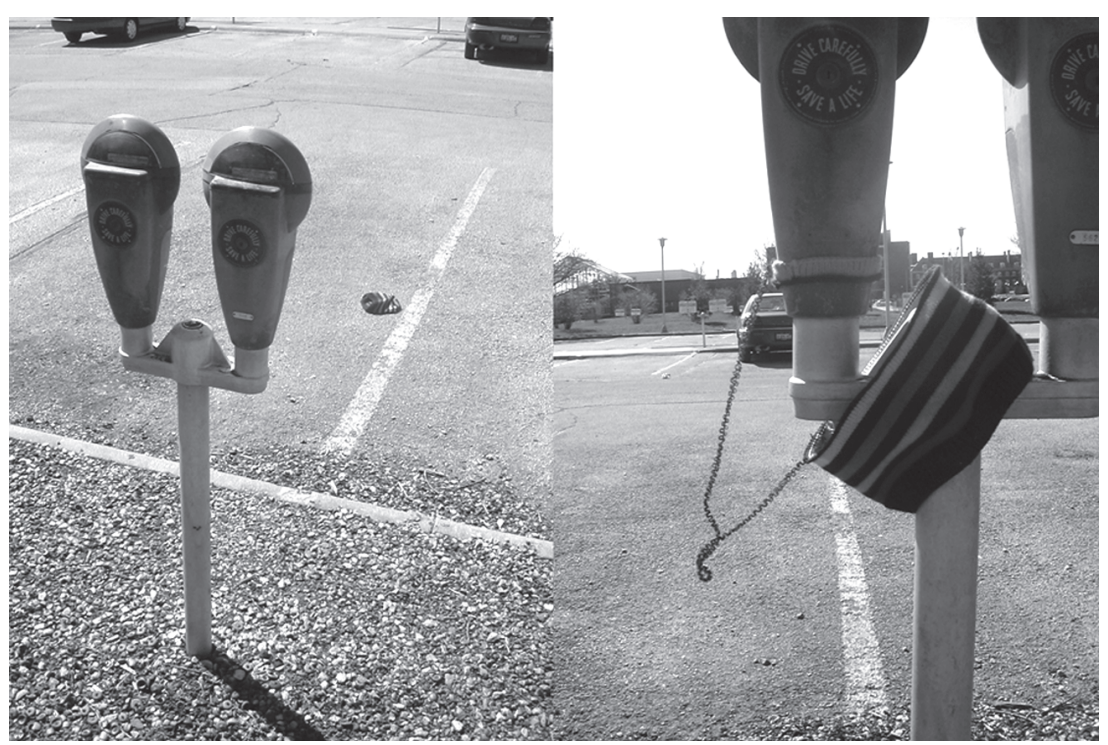

Figure 2: 'Lost/Found knitting series - Knit Hat Parking Meter' by Meredith Warner. 
become location aware as a consequence of their encounter. This location awareness is exactly what both the manufacturer of the sat-nav wants the device to be and the user of the sat-nav seeks to become by buying the device. At the end of the article, I will elaborate as to why there should be more similarities between the way lost mittens are being situated by Warner and the way human beings should ideally be situated by the sat-nav.

\section{To (never) feel lost}

'We'll take you there', the corporate slogan of the main sat-nav manufacturer Garmin insists. The equally influential company TomTom claims that it is manufacturing 'innovations to make life easy'. Both catchphrases sell the dream of the friction-free travel experience, where driving through unfamiliar terrain becomes as easy as just driving a car and where the differences between driving in known and unknown areas diminish. The website of TomTom states: 'independent research proves that TomTom products have a significant positive effect on driving and road safety.' (TomTom 2008b) According to the corporate website, the company's first move into the sat-nav market was to make GPS modules for PDAs, which quickly developed into full-scale navigator devices:

[. . . ] the need to go from A to B the easy way went way beyond PDA owners. Other people needed to navigate, and they would need a single product that was very, very easy to use. Like a map, or asking a local, it shouldn't need a manual.

(TomTom 2008a)

The rhetorics on what it means to travel are interesting even if the two quotations are primarily intended for promotional and not explanatory purposes: First, they assume that travelling is a matter of arriving at a destination (going 'from A to B the easy way') and not about the journey itself - about the product and not the process one might say. Second, satnavs are considered safer than paper-based maps because people do not have to read and drive at the same time, compare the 'significant positive effect'. Third, while maps and locals are articulated as something that never need a manual, by even mentioning them TomTom implicitly refers to the fact that from many people's experience both are also slightly traumatic: Maps are often out of date and/or impossible to decipher and oftentimes a manual to locals would be very useful since cross-cultural and interpersonal communication is complicated. Pushing it a bit further, it could be argued that the quotations implicitly claim that travelling is less stressful if one manages to connect as little as possible to the outer world unless one intentionally makes an effort to do so.

Garmin's slogan referenced above carries similar connotations, which are further stressed when the company explains on its website that it has been making positional and navigational devices for all purposes since 1989 with the aim 'To create navigation and communication devices that can enrich our customers' lives' (Garmin 2009). Following this, life is not enriched when one engages with the surroundings encountered en route; 
life is enriched when one succeeds in arriving seamlessly at one's destination so that one has energy for the experiences awaiting. With its continuous display of the immediate route ahead and its always updated timing information, the sat-nav will always point forward towards a potential experience at the destination. By inference this incessant pointing forward means that any given location is never a point in its own right unless it is the destination. Maybe there is something about this concept that makes the driver less inclined to pay full-hearted attention to her immediate surroundings as they are only points on a path leading somewhere else? This, I will expand on later.

\section{Tactics of situating}

'Space is a practised place' Michel de Certeau states in his famous book The Practice of Everyday Life (Certeau 2002 [1984]), which is a philosophical investigation of everyday life in cities. With this, Certeau partakes in the discussion about the nature of locations - on how a location can be both an objective or almost factual notion as well as a 'container' of subjective and felt experiences. In this much-cited phrase, Certeau coins his understanding of the terms space and place, which again refer to an important distinction between a strategy and a tactic. In Certeau's view, these terms cover most aspects of everyday life, but with regards to the city, a strategy is the unified whole of the city as a concept - a plan one might say - whereas tactics is a way of appropriating the principles that the strategy has sought to stimulate. The notion of tactics is not to be understood as a revolutionary practice but the terms are rather to be understood as a way of articulating the differences between planning and performing a city structure. Jensen and Lenskjold summarize Certeau's main argument as follows: 'Certeau highlights the ways that individuals by means of everyday tactics and 'silent procedures' escape the control of material and abstract institutions and create their own interpretations or writings of the city.' (Jensen and Lenskjold 2004)

The difference between strategy and tactics also articulates the difference between the elevated and the embedded view of the city, and thus the difference between the map and the felt experience of the city structure. Applying the myth of Icarus and Daedalus to describe how a city can be experienced from two perspectives, Certeau argues that the city can be accessed in two ways: from outside through the map or from within as a pedestrian (Certeau 2002 [1984]: 92). As shown earlier, this is primarily to be understood as conceptual or abstract theory but it is also meant quite literally. On a conceptual level, Certeau clearly uses the image of the wandering, and thereby tactic, individual as a concrete metaphor of how a city layout is always embedded with and within political and institutional agendas. On a literal level, Certeau's notion of tactics is a matter of establishing subjective relations between the traveller/pedestrian and the city. In this way, the notions of the inside (the embedded) and the outside (the elevated) are also accounts of the difficulty in combining the two perspectives into one image: 
It is true that the operations of walking can be traced on city maps in such a way as to transcribe their paths (here well-trodden, there very faint) and their trajectories (going this way and not that). But these thick or thin curves only refer, like words, to the absence of what has passed by. Surveys of routes miss what was: the act itself of passing by. [ . . . ] They allow us to grasp only a relic set in the nowhen of a surface of projection. Itself visible, it has the effect of making invisible the operation that made it possible. These fixations constitute procedures of forgetting. The trace left behind is substituted for the practice.

(Certeau 2002 [1984]: 97)

Certeau argues in the above quotation that trying to let the one perspective incorporate the other, especially aiming to make strategic tracings of tactic performances of the city structure, will result in a false knowledge of the cityscape as tactics do not translate into strategies; one cannot elevate the embedded view.

The distinction between the objective and the subjective experience of a location, or between the controlled and the loose relation between the subject and her surroundings was also a main area of investigation for the Situationist Internationale in the 1960 s and their Lettrist predecessors. With the advent of the sat-nav or, more precisely, the GPS tracking device, especially the psychogeographical explorations of the Situationists have become a popular reference. Psychogeography is about acknowledging the specificity of a location (thus investigating the 'spaceness' of a place in Certeau's terms) and the Situationists invented a range of tactics in order to explore the psychological geography of especially Paris. In a set of manifestos for exploring cities, Guy Debord - one of the most influential members of SI - accounted for how a thorough investigation of the inner life of a city is essential if one wishes to get to know its 'heart' as described in 'Introduction to a Critique of Urban Geography' (Debord 2006 [1955]). The dèrives of the situationists (Debord 2006 [1958]) thus challenged the dominance of the strategic city and the elevated perspective by encouraging people to investigate the frictions between the map's representation and the encounters at street level. These tactics involved a great deal of performing of locations: in the search for 'their principal axes of passage, their exits and their defenses' (Debord 2006 [1958]), participants literally had to walk the streets until they would speak the same language as the streets until the atmosphere of the different neighbourhoods would reveal itself. At this point in time the objective street map would have lost all meaning and participants, now completely embedded in the perspective of the street, would be able to construct subjective maps (literally or figuratively) of 'exits', 'defenses' and 'the distances that actually separate two regions of a city, distances that may have little relation with the physical distance between them'. In short, the participants would be situated - grounded and attentive to details.

The focus on the specificity of any given location and the potential experiences that await around literally every corner, is also prominent in the work of the Wrights \& Sites collective (formed by Stephen Hodge, Simon Persighetti, 
Phil Smith and Cathy Turner) that presents a contemporary variant of the Situationists' walking practice. Through workshops, exhibits, site-specific performances and not least guide books that aim to 'mis-guide' the participant rather than guide her in a traditional way, Wrights \& Sites aim to make people 'constantly re-think the city' (Wrights \& Sites 2004) by setting up specific parameters through which the city can be explored. One example is to transform the perception of something normally considered a nuisance into a little pocket of time where one rediscovers the plural perspectives of urban space: '[roadwork] is generally regarded as an inconvenience. On a mis-guide it can be seen in a different light [. . .] you could consider the roadworks as a free open-air exhibition of earthworks and archaeological revelations.' (Hodge, Persighetti, Smith and Turner 2006) A mis-guide is described as something that 'is completed by the walker and becomes specific to its location only in the walking' (Wrights \& Sites 2008), and the purpose is to explore new ways of engaging and interacting with the well-known:

we do not see the dérive as a self-contained movement through space, even when undertaken by a group. There is always the possibility of interaction with the material elements around us and with the other inhabitants of the city. We are not detached observers but participants. This means that our walks encourage new exchanges and meeting points, as well as new perspectives.

(Wrights \& Sites 2004)

Especially the group's insistence on the subjective and engaged relationship with the location - 'We are not detached observers but participants' is in direct opposition to the sat-nav's paradigm, which is based on always moving on to more exciting places as I argued earlier.

Since actual movements can now be traced accurately and automatically and be overlaid on an actual map, people can let software generate maps of their everyday movements through locations thereby automatically figuring out the pivotal points of the urban environment. Sometimes it is used for mere fun as in the Brighton Elephant drawing (Wood 2001) (see Figure 3), where the drawing of a large elephant is performed in the streets of Brighton by help of a sat-nav that registers the route and maps it onto a 'regular' map of Brighton. The same technique is used by the Dutch artist Esther Polak when she creates her artworks. Since 2002, she has developed several digital artworks that record and map the trajectories of other people; 'Amsterdam Realtime' is especially clear when it comes to representing a city from the perspective of the way individuals actually use it (see Figure 4). (Polak and Society 2002)

While this practice bears some resemblance to the psychogeographic practice of the Situationists there are important differences that are rarely recognized, the most important of these being the idea of automating a subjective experience. In Certeau's terms, the inside tactics of the participants are sought translated into the outside strategies as they are present in the city structure. As stated previously, a large part of the psychogeographical 


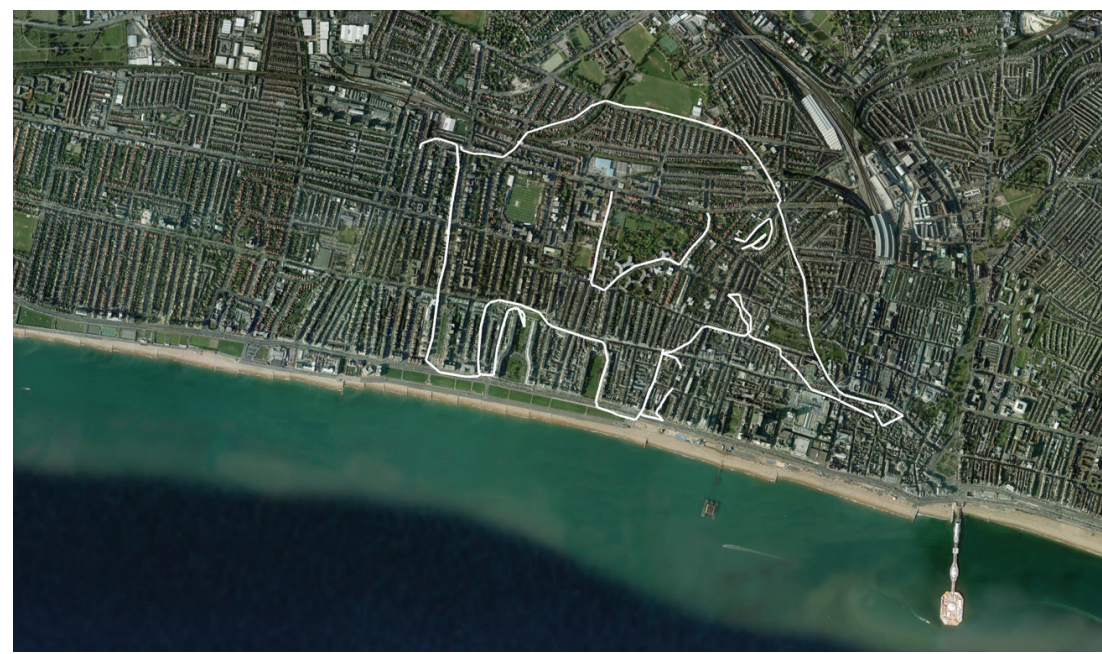

Figure 3: 'The Brighton Elephant', Jeremy Wood. The Elephant is comprised of data from a drive recorded by a sat-nav, which were subsequently automatically mapped onto a regular city map.

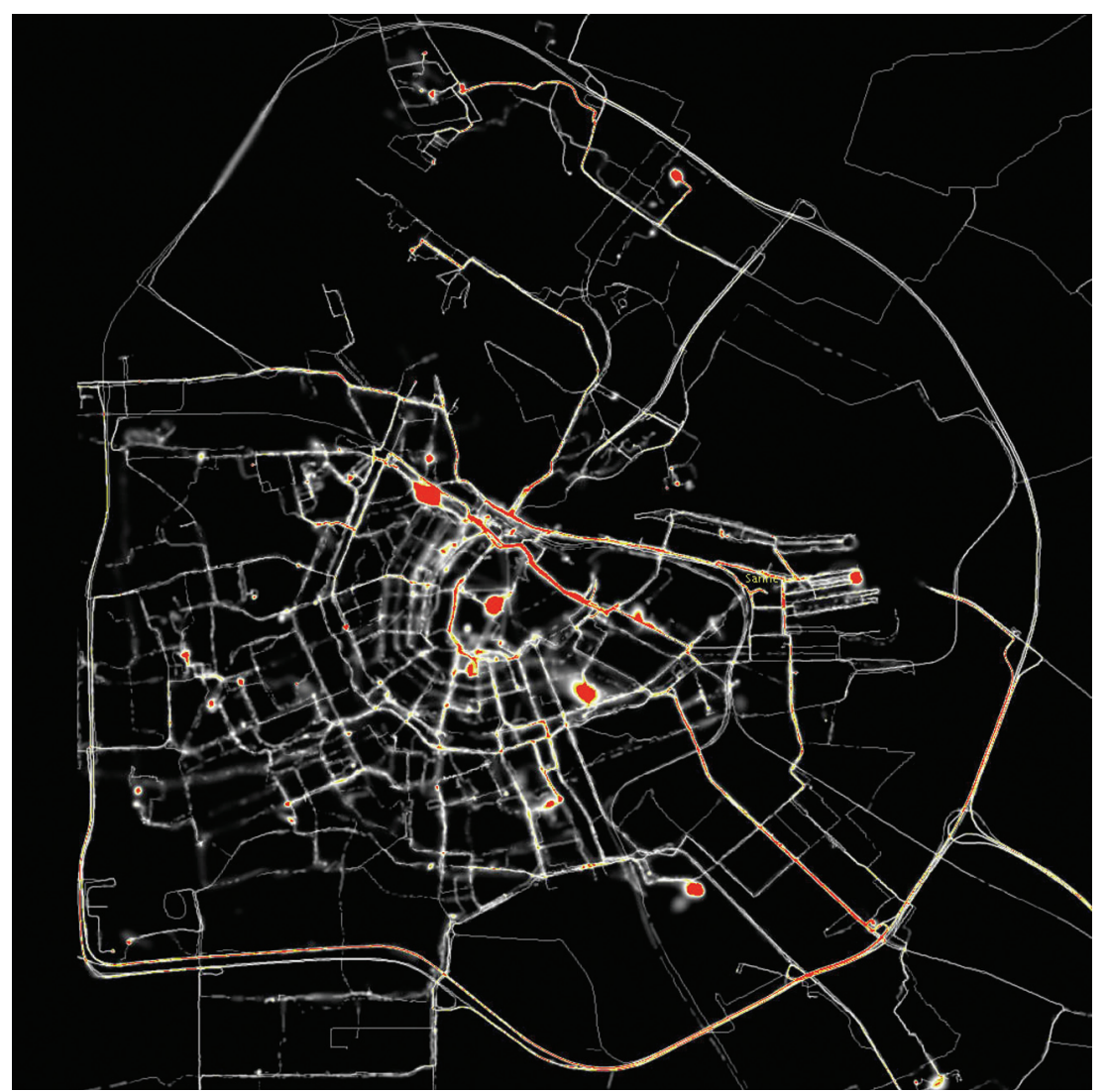

Figure 4: A map from 'Amsterdam Realtime' by Esther Polak and Waag Society. Trajectories of citizens of Amsterdam are recorded and mapped onto a representation of Amsterdam as it is used on a daily basis. 
practice of the Situationists was to negotiate the nature of the experiences encountered en route; to perform the city's layout through an active engagement in the practice of discovering atmospheres and contrasts. In his discussion of the Situationist city, Sadler describes the parameters that the Situationists were navigating by when they experienced, investigated and performed the atmosphere of the streets as follows:

The unities of ambiance [atmospheric pivotal points] were constituted by many things, especially the "soft," mutable elements of the city scene: the play of presence and absence, of light and sound, of human activity, even of time, and the association of ideas. (Sadler 1998)

Thus, 'measur[ing] the distances that actually separate two regions of a city' (Debord 2006 [1958]) is not a matter of keeping exact track; mapping is not the primary purpose of the psychogeographical 'measurings' because it is all about engaging in the flow of experience and about recognizing the unspectacular experiences literally offered everywhere you go. Any location thus becomes a location in its own right.

To appropriate the above performative practices and align them with the notion of finding one's way through any area not known by heart (or by body), the three perspectives of the Situationists, of Wrights \& Sites, and of Certeau highlight that it is essential to situate oneself within the location and the environment one finds oneself in at any given time. As is obvious from the many examples of stray drivers, the sat-nav does not seem to succeed in performing this task.

This means that even though the sat-nav is challenging the authority of the overview map in ways that, superficially seen, seem to resemble Certeau, Debord and Wrights \& Sites' appeals to reclaim the streets, it is still anything but: While it allows for the driver to focus less on the paper map in the codriver's lap, it simultaneously makes her even more subject to the authority of the sat-nav as she is unable to escape the logic of navigation imposed on her by the device. The sat-nav seemingly enables the driver to engage deeper with her current location because she can focus on the relation to the streets and not on the relation to the map. Or, to put it in Wrights \& Sites' terms as introduced in the above quotation, the sat-nav theoretically encourages 'interaction with the material elements around us' instead of encouraging interaction with the map. However, the sat-nav's way of 'automating' the relation between the driver and her surroundings is one of the key reasons as to why this encouragement seems to happen on a theoretical level only.

\section{Mapping trajectories}

The very concept of an automated and localized navigational aide embodies the notion of seamless travelling: even when you decide to perform an explorative movement through the landscape like the Situationists, the satnav will make sure that you will never be lost for real. And when using the sat-nav in order to travel easily from A to B, satellites will always be watching. Should you accidentally travel another route than the one suggested by 
the sat-nav, the device will immediately advise you to turn left, right or around until you are back on track.

In the super-structure of many North American cities the map is embedded into the streets whose names also serve as navigational aid - to find your destination you only need the address and not an accompanying map. An address in the format of 7635 th Ave in itself reveals that the street lies between 4th and 6th Ave, that it runs North to South and that it is the 3 rd door in the 6th house in block no 7 counted from the beginning of the avenue. However, a very little part of the world is carved up in a grid plan, which is one reason why sat-navs are becoming increasingly popular.

Both Board (1978) and Peacocke (1983: 76) explain that using a map requires several layers of simultaneous interpretation as it is very important that the map user incessantly performs location tracking in order to continuously link the actual position to the position on the map. The sat-nav automatically performs this linking task, and as a consequence thereof, the impulse to orient oneself at a location and pay attention to the route may not be as urgent as if the mapping device not been location aware.

With regards to the 'nature' of the map cognitive psychologists Cornell and Heth point out that a map is always a symbolic representation of space. This spatial representation comes in two basic shapes that each results in a specific way of creating a trajectory, that is in two different ways of performing space: as a route description used for the procedural task of following a route (navigation) and as a map supporting a more explorative movement from A to B (wayfinding) (Cornell and Heth 2000). The difference between navigation and wayfinding can also be expressed as the difference between following a predefined sequence and creating a sequence based on a number of selections. With regards to how one connects with the location one travels through, both navigation and wayfinding requires that one pays attention to the surroundings. But where the purpose of navigational attention is to locate the described route, thereby performing a specific sequence by help of pre-defined signs, the attention in wayfinding is directed towards interpreting possibilities for movement in order to create a subjective sequence. Both paradigms are useful, although for different purposes, and they establish different ways of relating to the location one travels through.

The sat-nav is obviously based on the navigation paradigm; no wonder it is also often called 'a navigator'. It automates the navigational attention by locating and keeping track of the pre-defined sequence of the route description. Following Cornell and Heth's studies on the relationship between the location and the map, this automation means that the cognitive load of keeping track and thus also of paying attention is no longer as present in the user. Using another terminology one could say that she is no longer situated because the link between location and herself is taken over by a computer.

\section{Embodiment perspectives}

The current sat-nav paradigm is based on and quite closely emulates oldfashioned analog map-models. There has been an almost literal adaptation 

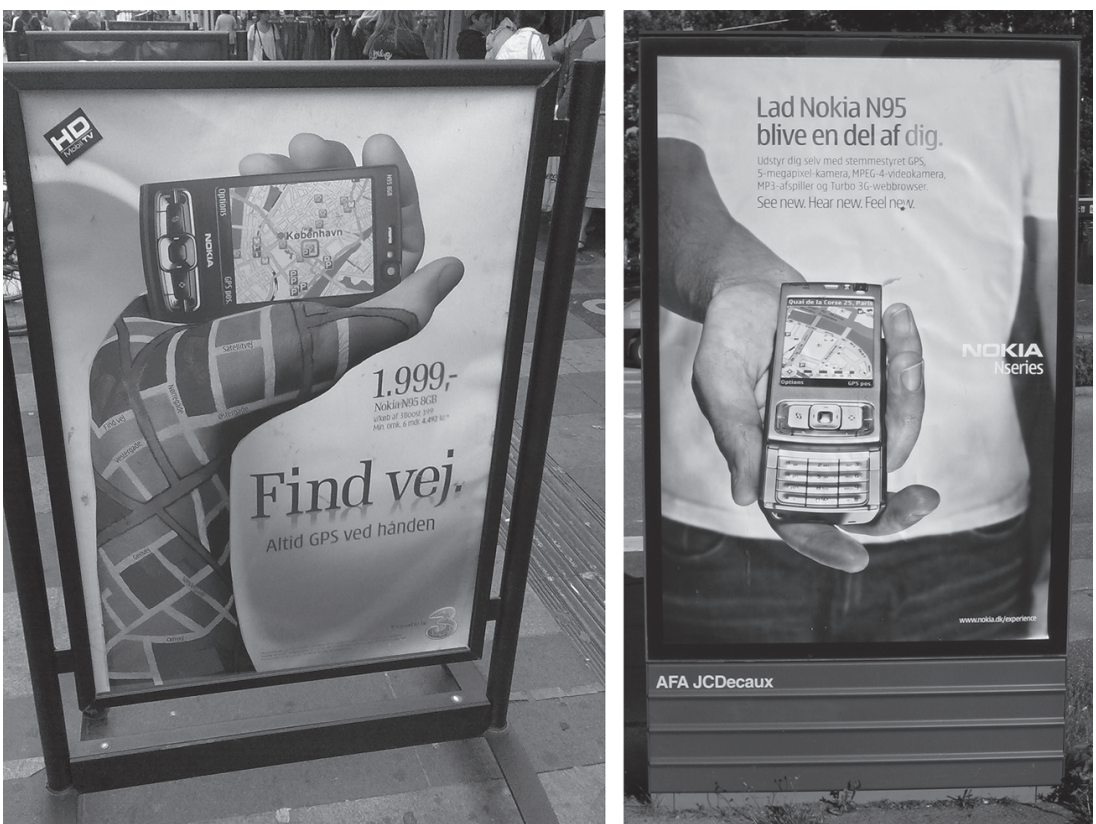

Figure 5: Two Danish Nokia street advertisements for the N95 mobile phone that also contains a sat-nav module. The left ad reads 'Let Nokia become a part of you'. The right ad reads 'Find your way. Nokia is always at hand'.

of an old technology's idiom (the physical paper map) into a new technology; one kind of interface has been blindly transferred onto another - the same can be observed with regards to online maps. The sat-nav could have been the perfect example of how the two disciplines merge but ironically, the sat-nav is not a hybrid but a bastard. This becomes clear when we look at how sat-navs articulate the role of the traveller's body: the body is by nature always in the embedded, inside, or tactic end of the navigation spectrum. Nonetheless, many ads for sat-nav enabled devices articulate the body as if it is part of the elevated and outside perspective as is clear from the two Nokia street advertisements (Nokia 2006, 2008) as shown in Figure 5 .

These two advertisements are examples of how sat-navs are visualized as extensions of the user's body, or as a technological example of MerleauPonty's notion of the 'bodily auxiliary, an extension of the bodily synthesis' (Merleau-Ponty 2005 [1962]: 176) While this perspective of the map being embedded in the body would be the inside perspective in light of both Debord and Certeau, which again can be likened to the navigation perspective of Cornell and Heth, it is clearly visualized as an outside and elevated perspective in the advertisements because both the displays on both phones show a map in the wayfinding map tradition.

In the left advertisement, the phrase 'Let Nokia become part of you' obviously refers to the way that people nowadays tend to be closely connected to their mobile phones as most of us carry them with us everywhere 
we go. Additionally, in the advertisement's visual presentation of the phone, the built-in satellite map is offered as an extra bonus and a precious gift to the potential buyer while it is also held like the needle in a compass, clearly capable of steering the owner through his surroundings. So while the mobile phone as a concept is already embedded in our lives, which is articulated in the advertisement's phrase, this mobile phone is offered as something special because it will also embed the owner/buyer/user of the mobile phone in his physical surroundings.

The advertisement to the right takes the idea of the phone being an extension of the body even more literal as it suggests that with this sat-nav enabled phone the user will literally be inscribed by the map. The difference between the user's hand and the phone's interface diminishes and the phone seems to have become part of the user's sensorial apparatus. In this advertisement, the map is also following the wayfinding paradigm, but unlike in the ad to the left, this phrase 'Find your way. Nokia is always at hand' actually fits the map paradigm. However, by visually merging the elevated map with the embedded perspective per se, the body, the advertisement still promises that the user will be able to perform the streets as if she were native to them.

In short, both advertisements visually promote the sat-nav enabled mobile phone as a wayfinding device, but it is in reality a navigation device because it provides a route description and not an overview map. Basically, these advertisements state that users will be maneuvering a territory with the all-knowing view from the elevated outside, while in reality they are actually navigating a route description most of the time without having the knowledge inscribed in the situated and embedded body. And because the very concept of the sat-nav is to always automatically perform the situating part of the navigation (or at least this is what it is supposed to do, although the driver finding herself in the water-filled ford might beg to differ) this combination of a lacking overview and no obvious need to situate oneself by meticulously comparing route description with surroundings is creating a non-situated performance of the streets. It is as if the Situationists had performed their dérives while deprived of their senses.

The attempt to use the body as compass is also seen in this curious invention from 1924 (see Figure 6).

The navigation device Improvements in or relating to golf or like scoring tablets patented in 1926 by O'Loghlen and Levi (O'Loghlen and Levi 1924) also came with route-strips (as shown in the picture) and had the size and form of a wristwatch. There are several reasons why it would be smart to always have the map at hand (literally speaking), one of them is of course that it is easy to relate to when driving. On a more abstract or performative level, however, this direct linkage between body, map, and landscape also clearly suggests an idea of the body as the real mediator between the landscape traversed and the self. With the map almost inscribed on the body, as in the Nokia advertisement only not as radical, the device also expresses a desire to almost intuitively know one's way around even unknown landscapes. This old wristwatch route description is, however, probably closer 


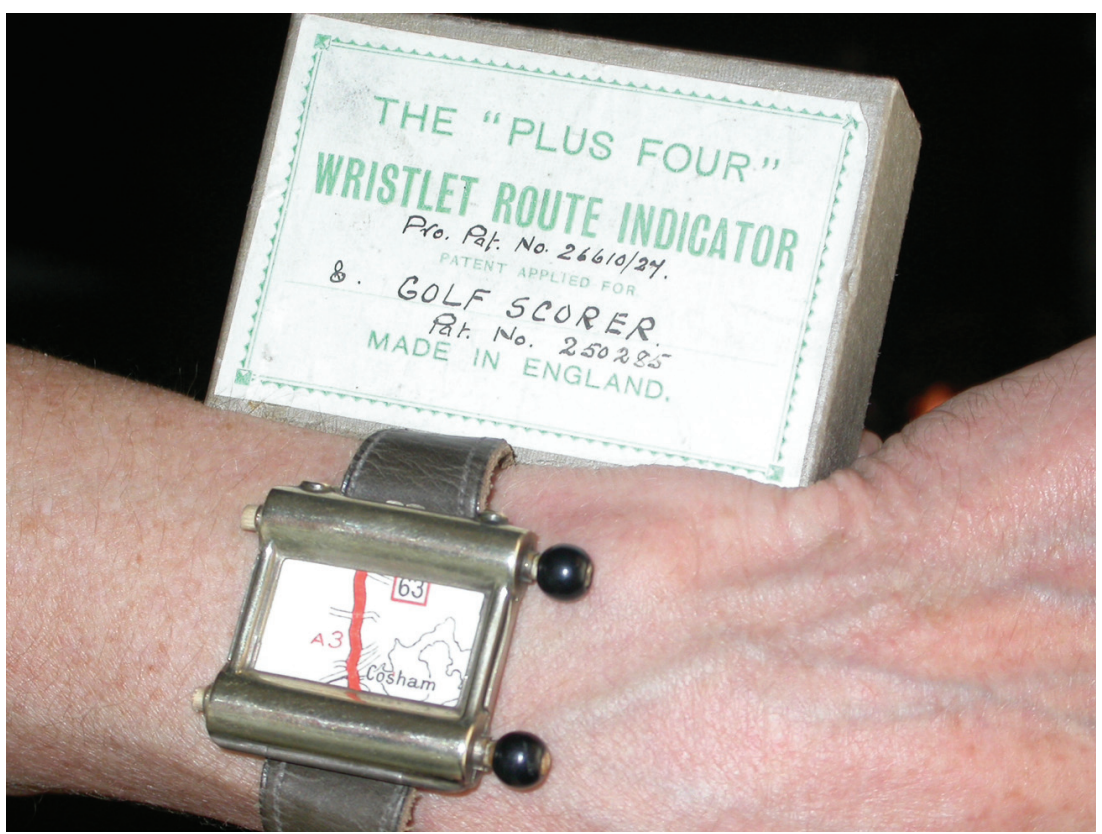

Figure 6: The 'Wristlet Route Indicator' patented by O'Loghlen and Levi in 1926.

to the goal than the modern phone, because the technology used - as well as the limited map displayed at any given time - do not take over control. In order for the route description to make any sense, it is crucial that the driver constantly pays close attention to the surroundings; constantly situates himself. The small and limited appearance of the wrist watch's route description forces the driver to be exceptionally attentive, to move slowly forward, and maybe even stop and leave the car sometimes. This paying attention to details is similar to the way Warner needs to be attentive to details when she situates the alien mitten. This comparison is, of course, not to be taken literally but if we understand the differences and similarities as a matter of performing a location in order to understand it - in order to become situated - the need to pay close attention seems to be crucial. And the need to pay close attention to more than just driving the car is no longer present when the automated technology overrides one's individual tactics with its strategic agenda, compare Certeau.

Historically, the two perspectives of the embedded and the elevated were closely connected as the bird's eye view of the map stemmed from the cartographer's bodily explorations and investigations in the field. In order to make the map he had to literally embed himself in the landscape thus transferring his embedded knowledge to an elevated perspective. Later on, planes, helicopters and satellites took over from the embodied investigations and provided an objective and non-embedded view. According to the 2006 exhibition London: A Life in Maps in the Pearson Gallery at the British Library (now partly accessible online), the early history of the London street map and map guide reflects this emphasis on field experience as maps 
often referred to distances in 'experienced time' and to objects that were only viewable from the street perspective even though the map applied the elevated perspective.

As is obvious from the above, the localized and detailed route description aiming at passing on information when needed instead of giving an overall picture of the area to be travelled, was not invented with the sat-nav. What is new, however, is the route description's ability to be automatically localized although the ability to automatically situate the driver does not follow in tow. In fact, the opposite seems to happen in the straying incidents that form the outset of this article's investigations.

People were probably also lost in 'the good old days' but even conceptually the difference is big: the sat-nav supposedly removes the need to pay close attention to the relations between the map and the actual world because even if you get lost you know that the device will get you on the right track again as I argued above. On this conceptual level, the difference between automated and manual attention is, however, important because automation removes the intermediary role of the map. Expressed by help of the metaphor provided by Warner's locative knitting project, automation makes the map act as a gatekeeper between location and representation by situating technology and not the driver even though the advertisements from Nokia in Figure 6 suggest otherwise. Thus, the device fails to act as an intermediator, which would have forced the traveller to intertwine the actual location with its representation, thus effectively forcing the traveller to become as situated as Warner's mittens.

\section{How to situate an alien}

Melodious Walkabout by Etter and Specht (2005) is an example of how Warner's situating principle of performing a location could be transferred onto a sat-nav setting (Etter and Specht 2005) (see Figure 7).

The performative artwork is an example of how a sat-nav can serve as catalyst of an individual's active engagement with a location. Melodious Walkabout is an audio-based wayfinding concept. The sat-nav software is installed on a mobile device on which the user plays her music as she would normally do; this could for instance be the Nokia N95 displayed on the advertisements in Figure 5. By changing parameters in the user's own music, the system now guides the user by manipulating the music in real time. The design metaphor of Melodious Walkabout is that of moving towards an outdoor concert by listening to the music's sound and volume; the louder and clearer the music, the closer you are to the concert location. Two parameters are manipulated: frequency spectrum and left to right panning. If the user is headed too far to the left of the destination, the music becomes louder in the right ear and vice versa. Furthermore, frequency change is used to let the user know when she is walking away from the music instead of towards it. If your music sounds correct then you are on the right track, otherwise it is distorted and non-balanced at various degrees.

Among other things Melodious Walkabout is interesting because of how it creates relations between the interface and the 'real' world as it highlights 


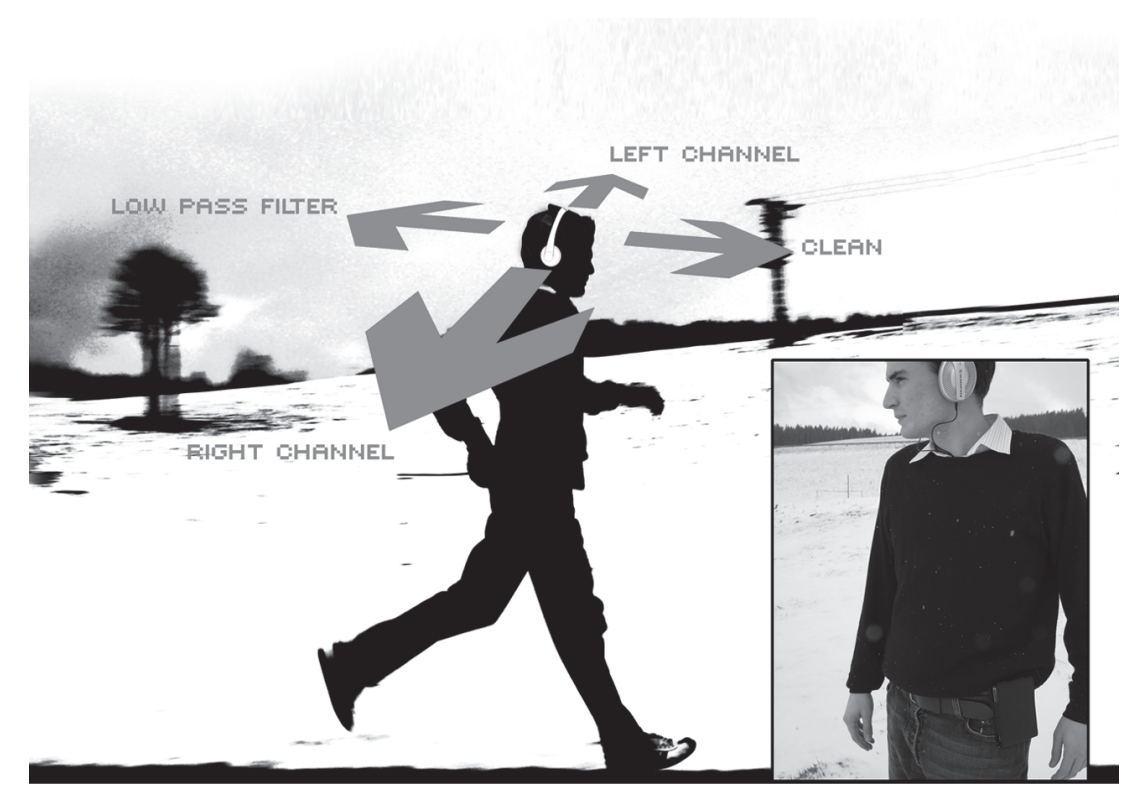

Figure 7: The 'Melodious Walkabout' navigation concept by Etter and Specht changes parameters in the wearer's music to communicate the direction of the user's goal.

the frictions between what the technology tells you to do and what the real world allows you to do. It embodies the dynamics between strategy and tactics; or between being a lost and a situated alien. In its performative approach to moving from $A$ to $B$, the device provokes an immediate awareness of the city instead of covering it with a layer of friction-free commands like the sat-nav does. The participant of Melodious Walkabout may not always be travelling the optimum route but she is on the other hand never allowed to become a senseless robot reacting blindly to authoritative instructions. Because of the deliberately vague instructions, she will always be forced to employ her own tactics in order to find her way through the city's strategic structure. The wayfinding paradigm of Melodious Walkabout is based on loosely choreographing the relations between city, traveller and interface so that the traveller can perform her own version of the trip from the highly embodied and embedded perspective of the streets.

As I remarked earlier, the Nokia phones in Figure 5 embody MerleauPonty's 'body auxiliary' on a superficial level. The sat-nav device in Melodious Walkabout, however, is actually a 'body auxiliary' because of the way it puts the participant's body back into play as the crucial part in the body-technologysurroundings triad experienced by the participant while she interprets the streets through what her own senses tell her about her physical surroundings as well as what technology tries to tell her about the aspects she is unable to sense on her own. This way of using the sat-nav technology takes seriously the interplay between the body's senses and the senses of technology.

Following the Situationists' call for subjective mappings, and following Certeau's call for not confusing a strategy with tactics, Melodious Walkabout 
seems to take seriously the performative potentials of technology: Etter and Schecht do not fall for the temptation of making the user's body and its senses obsolete or secondary. Rather, Etter and Schecht manages to integrate the body of the alien traveller into the streets while keeping technology in command of only the things we cannot see from our embedded street perspective.

The artefact adds a digital layer to the physical world, a principle that new media theorist Lev Manovich terms hybrid space and describes as 'overlaying the physical space with the dynamic data' (Manovich 2006: 223), but it does so without overshadowing the bricks and mortar qualities of the physical world. Unlike the sat-nav, Melodious Walkabout is encouraging reflection, afterthought and, not least, location awareness by establishing a contrast between the physical reality encountered en route and the potential robotic aspects of navigation appearing as a consequence of using the almost intuitive metaphor of walking towards a sound source.

Consequently, in Melodious Walkabout the body's senses and the senses of technology are effectively combined in a way that quite closely resembles Warner's re-knittings. One could argue that until the incident of the re-knitting performance, both Warner and the mitten have been aliens, in much the same way as the participant in Melodious Walkabout is situated through fulfilling the device's demand of a performative approach to wandering the city's streets. When Warner re-knits the alien mitten to its found location, she is also becoming situated herself; for every stitch she knits, both the mitten and Warner herself are closer to becoming embedded in the strange structure of the city landscape. Warner is not only reconnecting the lost items to their surroundings - giving them a new home, one could say - but her own practice is also filled with slowness and reconnections. She takes her time when she finds a lost knitted object: she unwinds the yarn, identifies a nearby and suitable object to re-situate the yarn and make a new and fully embedded knitted object, and lastly she spends a considerable amount of time knitting it again. Warner celebrates the slow, meticulous and individual connection to the location by engaging directly with both the alien and the local. In this process, she forces herself to also (re)connect to the space, to situate herself concretely as well as metaphorically in her current location instead of rushing off to her next destination. In this way, she emphasizes the process and not the product; emphasizes how the yarn need not be repurposed into something useful but may instead find a new and more poetic life as an embedded ornament literally growing out of the situation.

With the performance practices of Warner and Etter and Specht in mind, how can we then understand the sat-nav as a device that might enable us to become located whilst in transition? Most importantly, both address the inherent contradiction between being situated and being in transit, and they do so by confronting the participant with the notion (and lack) of seamlessness. Warner's practice as well as Etter and Specht's concept is designed for becoming aware of boundaries and thresholds through exploring them instead of trying to cover them up. The current sat-nav clearly aims to disguise the seams between knowledge and ignorance by making 
all locations equal and by transforming any location to a point on a route towards a destination. Contrarily, Warner merges artefacts that would normally never be combined, and Etter and Specht have found a way to make the difference between destination and location visible through the technology employed by the participant. The Melodious Walkabout software is destination-aware but leaves the location awareness to happen through the participant's senses. Consequently, the way Melodious Walkabout requires the participant to engage herself actively in the process of 'getting there' in order to arrive anywhere at all could be a way forward for the sat-nav companies.

\section{Concluding remarks}

When Debord and Certeau denounced the map in favour of the subjective experience on the street level, they were referring to how the city map expresses a totalitarian logic as the cartographic features are signs of authority and control. The logics or tactics of Debord, Certeau and Wrights \& Sites are based on bringing back the pedestrian's own feeling of the city's appearance as it is experienced during the sensory-driven walks through the streets. When transferring this logic to the principle of 'getting there', it is not as much a matter of mapping or not mapping, as it is a matter of how the map (re)presents the world. In this respect, and this might sound contradictory at first, the sequential navigation by help of a route description equals the authoritarian logic as described by Debord; the driver of the car is at the very outset left with little choice but to obey orders and with little choice but to accept that the sat-nav is in control and assesses the location correctly.

As the examples of lost drivers show, the sat-nav does not always assess the location correctly, but it would appear that people only figure this out by the time it is too late. One could say that the territory has become composed from the map; it has become an instance of Baudrillard's hyperreal where the map is substituting reality:

It is no longer a question of imitation, nor duplication, nor even parody. It is a question of substituting the signs of the real for the real, that is to say of an operation of deterring every real process via its operational double, a programmatic, metastable, perfectly descriptive machine that offers all the signs of the real and short-circuits all its vicissitudes.

(Baudrillard 1994 [1981]: 2)

In this light, the sat-nav is a descriptive machine, describing reality so meticulously that the machine no longer duplicates, but creates its own corporeality. The map has become hyperreal, 'more real' than reality itself, making users trust the algorithms more than they trust their eyes.

In Certeau's terms, the sat-nav leaves no room for tactics because the strategic perspective has taken over completely - even though the strategic perspective is actually not the overview map but the route description when it comes to the automated sat-nav. Thus, as a route description the sat-nav fails to perform its location correctly. Contrarily, when one wishes to find a 
trajectory through the unknown territory between $A$ and $B$, the strength of the overview map is that it opens up for interpretation of possibilities, and in this particular respect the perspective of the overview map is the preferred option if the sat-nav location-performative paradigm needs to be either the map or the route description.

The best option, however, seems to be to seek an explorative, embedded paradigm like the one offered by Melodious Walkabout. It may not be the fastest option at all times, but at least on a conceptual level, the artwork makes room for taking all sensorial input into account in the process of exploring the streets as a canvas where the participant can 'write' her own city or perform her own understanding of the streets, compare Certeau's pedestrians:

They walk-an elementary form of this experience of the city; they are walkers, Wandersmänner, whose bodies follow the thicks and thins of an urban 'text' they write without being able to read it. These practitioners make use of spaces that cannot be seen [. . . It is as though the practices organizing a bustling city were characterized by their blindness.

(Certeau 2002 [1984]: 93)

Certeau thus argues that the blinded perspective of the embedded walker counts as the preferred option to the see-all perspective, as 'blind' walkers are freed from the strategies imposed on the city from 'above'. Without being in the blind state, they would not be able to be fully situated; paradoxically the blinding makes it possible for them to open their sensorial apparatus.

The sat-nav is totalitarian from the very outset, and this makes people blind in a different way than in the Certeau-ian sense. The wayfinding perspective, that is the possibility of encountering the city on one's own premises, is removed by the sat-nav while users still believe it to be intact. The device designs an experience of the location so abstract and permeated by the authoritarian logic of the itinerary that the user is unable to subjectively experience the specifics of her current location. Melodious Walkabout, on the other hand, presents an alternative as it forces the wanderer to take control of her own sensorial experiences all the while she literally performs the city's strategic layout. The concept thus questions the assumption that location aware technology automatically creates a location aware user, and the sat-nav technology is used to internalize the Situationist tactics of performing the streets until the individual becomes completely embedded.

With the small performative artwork of Meredith Warner we may even come to understand the dynamics of the sat-nav and reach a tentative explanation as to why people drive into lakes or suddenly find themselves alienated towards their current location. Warner's little poetic performance for one knitter, a mitten and a parking meter very precisely highlights how sometimes you need a helping hand to avoid getting lost in location, the important lesson being that in order to be situated at a location - in order to internalize and individualize it - one needs to perform it. Whether it is by 
help of a strange map, a mis-guide book, an audio-based direction provider, or small knitting needles that enable instant performative embedding into the current location.

\section{Acknowledgements}

This research has been conducted within the Digital Urban Living research project funded by the Danish Council for Strategic Research grant number 2128-07-0011.

\section{References}

Baudrillard, Jean (1994), Simulacra and Simulation, in Dalia Judovitz and Porter I. James (eds.), The Body, in Theory. Histories of Cultural Materialism (trans. Sheila Faria Glaser), Ann Arbor: The University of Michigan Press. First published 1981.

Board, Christopher (1978), 'Map reading tasks appropriate in experimental studies in cartographic communication', The Canadian Cartographer, 15: 1, pp. 1-12.

Bruxelles, Simon de (2006), 'Sat-nav Dunks Dozy Drivers in Deep Water', The Times, 20 April 2006, http://www.timesonline.co.uk/tol/news/article707216.ece. Accessed 20 February 2009.

Certeau, Michel de (2002), The Practice of Everyday Life (trans. Steven Rendall), Berkeley, California: University of California Press. First published 1984.

Cornell, Edward H. and C. Donald Heth (2000), 'Route Learning and Wayfinding', in Rob Kitchin and Scott Freundshuh (eds.), Cognitive Mapping. Past, Present and Future, London/New York: Routledge, pp. 66-83.

Debord, Guy-Ernest (2006), 'Theory of the Dérive', in Ken Knabb (ed.), Situationist International Anthology, Berkeley, California: Bureau of Public Secrets, pp. 62-66. First published 1958.

(2006), 'Introduction to a Critique of Urban Geography', in Ken Knabb (ed.), Situationist International Anthology, Berkeley, CA: Bureau of Public Secrets, pp. 8-12. First published 1955.

Etter, Richard and Marcus Specht (2005), 'Melodious Walkabout - Implicit Navigation with Contextualized Personal Audio Contents', Adjunct Proceedings of the Third International Conference on Pervasive Computing, Vol. 191, Munich, Germany, 8-13 May 2005, pp. 43-49.

Garmin (2009), 'Why Garmin?' http://www8.garmin.com/aboutGarmin/. Accessed 20 February 2009.

Hodge, S., S. Persighetti, P. Smith, and C. Turner (2006), A Mis-Guide to Anywhere, Exetor: Wrights \& Sites Publishing.

Institute of Advanced Motorists (2009), 'The Satnav Survival Guide', http://www. iam.org.uk/pressroom/drivingtips/Driving+tip+31+August+2007.htm. Accessed 20 February 2009.

Jensen, Rune Huvendick and Tau Ulv Lenskjold (2004), 'Designing for Social Friction: Exploring Ubiquitous Computing as Means of Cultural Interventions in Urban Space', in M. Agger Eriksen, L. Malmborg and J. Nielsen (eds.), CADE, Copenhagen: Copenhagen Business School.

Manovich, Lev (2006), 'The Poetics of Augmented Space', Visual Communication, 5: 2, pp. 219-240.

Merleau-Ponty, Maurice (2005), Phenomenology of Perception, Routledge classics, London: Routledge. First published 1962.

MetroUK (2007), 'Don't Follow the Sat Nav Says Sign', Metro UK, 18 February 2007, http://www.metro.co.uk/news/article.html?in article id $=37839$ \&in page id $=34$. Accessed 20 February 2009. 
Nokia (2006), 'N95. Let Nokia become a part of you'.

(2008), 'Nokia N95. Find your way. Nokia is always at hand'.

O'Loghlen, William Joseph and Emanuel Henry Levi (1924), 'Improvements in or Relating to Golf or Like Scoring Tablets', UK patent 250285.

Peacocke, Christopher (1983), Sense and Content. Experience, Thought, and their Relations, Oxford: Clarendon Press.

Polak, Esther and Waag Society (2002), 'Amsterdam Realtime', http://realtime. waag.org/. Accessed 20 February 2009.

Sadler, Simon (1998), The Situationist City, Cambridge, Massachusetts; London: MIT Press.

The Automobile Association (2009), 'Satellite Navigation and Driving. Ten Tips for sat nav Safety', http://www.theaa.com/motoring advice/safety/satnav-tentips.html. Accessed 20 February 2009.

TomTom (2008a), 'TomTom - The History', http://www.tomtom.com/about/about.php? $\mathrm{ID}=1 \&$ Language $=4$. Accessed 26 September 2008.

(2008b), 'Find Out More - About TomTom', http://www.tomtom.com/about/ index.php. Accessed 26 September 2008.

Warner, Meredith J. (2003), 'Lost/Found Knitting Series', http://www.knittingcommunity. org/projects/lostfound meter.html. Accessed 20 February 2009.

Wood, Jeremy (2001), 'The Brighton Elephant', http://www.gpsdrawing.com/ gallery/land/belephant.htm. Accessed 20 February 2009

Wrights \& Sites. (2008). 'About Wrights \& Sites', http://www.mis-guide.com/ ws/about.html. Accessed 31 March 2009.

(2004). 'Mis-guiding the City Walker', http://www.mis-guide.com/ws/ documents/citywalker.html. Accessed 31 March 2009.

\section{Suggested citation}

Hansen, L.K. (2009), 'Lost in location - on how (not) to situate aliens', International Journal of Performance Arts and Digital Media 5: 1, pp. 3-22, doi: 10.1386/padm.5.1.3/1

\section{Contributor details}

Dr Lone Koefoed Hansen is a researcher working in the interface between mobile media, urban space and everyday performativity. She is an associate professor at Aarhus University (Denmark) and recently received her Ph.D. degree, which focused on digital aesthetics and culture in the age of pervasive computing and mobile media. She is currently partaking in the research project Digital Urban Living (http://www.digitalurbanliving.dk/) and is a board member of the Digital Aesthetics Research Centre (http://darc.imv.au.dk/). Contact: Lone Koefoed Hansen, Department of Aesthetic Studies, Aarhus University. Langelandsgade 139, DK-8000 Aarhus C., Denmark.

E-mail: koefoed@hum.au.dk 